\title{
Experimental Study on Mechanical Properties and Energy Dissipation of Gas Coal under Dynamic and Static Loads
}

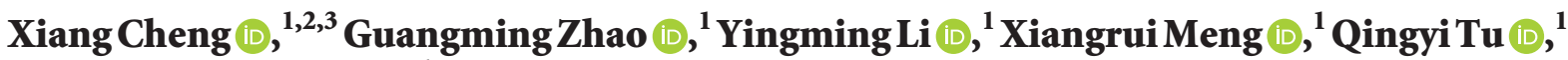 \\ and Chunliang Dong $\mathbb{D}^{1}$ \\ ${ }^{1}$ State Key Laboratory of Mining Response and Disaster Prevention and Control in Deep Coal Mines, \\ Anhui University of Science and Technology, Huainan 232001, China \\ ${ }^{2}$ Geological Resources and Geological Engineering Post-Doctoral Flow Station, Anhui University of Science and Technology, \\ Huainan 232001, China \\ ${ }^{3}$ Post-Doctoral Research Station, Huaibei Mining Corporation Limited, Huaibei 235006, China
}

Correspondence should be addressed to Xiang Cheng; cxaust@163.com and Guangming Zhao; guangmingzhao@163.com

Received 6 July 2020; Revised 22 September 2020; Accepted 2 December 2020; Published 16 December 2020

Academic Editor: Fengqiang Gong

Copyright (C) 2020 Xiang Cheng et al. This is an open access article distributed under the Creative Commons Attribution License, which permits unrestricted use, distribution, and reproduction in any medium, provided the original work is properly cited.

In order to study the mechanical properties and energy dissipation of gas coal under dynamic and static loads, the static loading and impact tests of different strain rates were carried out by the testing systems of SZW-1000 microcomputer servo pressure tester and separated Hopkinson pressure bar (SHPB) for gas coal in the Panxie Coal Field in Huainan City. In the test, the influence laws of various loading patterns on mechanical properties, failure characteristics, and energy dissipation of gas coal sample were analyzed. The results showed that the stress-strain curve of coal gas under dynamic load had no micropore compaction stage compared with that under static load. Dynamic compressive strength, dynamic strength growth factor, mixed dynamic elasticity modulus, and dissipation energy were all highly correlated with strain rate, whereas energy dissipation rate was uncorrelated with strain rate. In addition, the gas coal sample with lower strain had small dissipated energy, and it developed a splitting failure mode. With the increase of strain rate, the dissipation energy increased and the crushing degree of gas coal intensified, finally presenting a compressive failure mode. Based on the comparison of dissipated energy densities of different gas coal samples, given the same dissipated energy density, the failure degree of sample under dynamic load was higher than that under static load.

\section{Introduction}

With the increase of mining depth in coals, the dynamic phenomena (e.g., coal and gas outburst and rock burst) of coal-rock mass intensify increasingly, which threatens the mine safety and high-efficiency production $[1,2]$. During the exploitation, the coal seam is inevitably influenced by blasting stress wave and mechanical vibration. The formative stress wave causes additional disturbance to coal-rock mass and thereby forms the dynamic impact environment [3]. It has been demonstrated that mechanical properties of coalrock mass were highly correlated with strain rate [4-6]. Therefore, the study of dynamic mechanical properties of coal-rock mass is of important significance to understand the occurrence mechanism and prediction of coal-rock dynamic disaster $[7,8]$.
The separated Hopkinson pressure bar (SHPB) is a technique that is widely used in studying dynamic mechanical properties of coal-rock mass [9-13]. Mechanical properties of coal-rock mass under the impact load have attracted wide attention from scholars. Liu et al. [14], Wang et al. [15], and Fu et al. [16] carried out the impact loading experiments of Furong anthracite under different strain rates to study dynamic characteristics and energy dissipation, loss characteristics, electromagnetic change features, and constitutive model of anthracite sample. Shan et al. [17] carried out an impact dynamic test of Yunjialing anthracite, through which the dynamic mechanical constitutive model was studied. Meanwhile, the linear viscoelasticity model was constructed. Gao and Chan [18] studied the failure mode and strength features under the impact load for Yanquan anthracite, getting a threshold speed of anthracite. Wang 
et al. [19] studied the mechanical properties of water-containing candle coal under dynamic and static load combinations. Yu et al. [20] discussed the influence laws of temperature on dynamic mechanical properties for anthracite sample in the Datong Mine. Xie et al. [21] carried out the impact compression experiment of $1 / 3$ coking coal in Mine no. 10 of Pingdingshan under different strain rates. The above researches gain many significant results. Meanwhile, the law of energy dissipation has become a research hotspot. For outburst-prone coal as samples, Fan et al. [22] investigated the dynamic strength and energy dissipation characteristics laws of coals under different strain rates. Under different moisture contents, Lu et al. [23] quantitatively studied the dynamic failure energy dissipation characteristics of sandstone samples by the SHPB setup. Ping et al. [24] analyzed the energy dissipation law of limestone specimens after the freeze-thaw cycles.

However, most of existing papers focused on coal-rock samples, including gas outburst-prone coal, sandstone, and limestone. The mechanical properties and energy dissipation of gas coal under dynamic loads have not been developed. Moreover, all of production mines of Panxie Coal Field in Huainan City are coal and gas outburst mines. The coal type of the primary minable seam no. 13-1 (outburst coal seam) belongs to gas coal. Therefore, to guide mining technological revolution and further disclose the occurrence mechanism of dynamic phenomena of gas coal, it is urgent to study mechanical properties and energy dissipation law of gas coal under dynamic loads.

Thus, taking the gas coal (seam no. 13-1) of Panxie Coal Field as the engineering background, the static loading and impact test of different strain rates were conducted by SZW1000 microcomputer servo pressure tester and SHPB testing system. Mechanical properties of gas coal were studied under static loading and dynamic impact. Moreover, the dissipated energy density was analyzed under different loading patterns, aiming to comprehensively understand mechanical differences between static loading failure and dynamic impact failure for gas coal.

\section{Preparation and Physical Properties of Gas Coal Sample}

2.1. Characteristics of Gas Coal Sample. Gas coal samples used in this experiment were collected from seam no. 13-1 in the west 3rd mining area in the Pansan Coal Mine of Huainan Mining Group. Coal-rock mass presents black blocks or particles, with weak vitreous luster and black (or deep brown) striations. Bright coal is a main component for coal-rock mass, followed by vitrain and dull coal. The coalrock mass belongs to the semibright or semidark coal types. The apparent density is $1380 \mathrm{~kg} / \mathrm{m}^{3}$, the vitrinite reflectance is 0.86 , and the average ash content is $23.35 \%$ for raw coal. Coal property is manifested by the gas coal with low sulfur content and moderate heating amount. They can be used to prepare the representative coal samples.

$\mathrm{X}$-ray diffractometer (XRD-6000) and scanning electron microscope (SEM, Hitachi S-4800) were used to analyze the complicated microstructure and composition of gas coal sample. Figure 1 shows the photograph of X-ray diffractometer (Figure 1(a)) and XRD pattern (Figure 1(b)) of raw coal. It is found that the gas coal is mainly composed of $75-80 \%$ noncrystalline and $10-20 \%$ clay minerals. Among them, kaolinite content is the highest, accounting for more than $80 \%$ of mineral components, accompanied with few quartz, chlorite, calcite, and siderite. Furthermore, SEM images of gas coal under natural state are shown in Figure 2. From the different magnified images, we can clearly observe that the internal coal matrix has uneven surface, and it contains abundant original damage, such as microcracks and mesocracks.

2.2. Preparation of Coal Sample. According to regulations of Physical and Mechanical Property Test Method of Coal and Rocks (GB/T23561.7-2009), the large raw coals that were collected from underground well were processed in the laboratory. Cylinder samples $(\varphi 50 \mathrm{~mm} \times 100 \mathrm{~mm}$ and $\varphi 50 \mathrm{~mm} \times 30 \mathrm{~mm}$ ) were made by drilling, cutting, and grinding. After two-end grinding of samples, the flatness was lower than $0.05 \mathrm{~mm}$, and the depth of parallelism was lower than $0.02 \mathrm{~mm}$, thus eliminating test errors caused by the unevenness end of samples. The picture of gas coal samples is shown in Figure 3.

\section{Static Loading Test of Gas Coal}

3.1. Test Equipment. The static loading test was applied by using the testing system of SZW-1000 microcomputer servo pressure tester, including loading system and acoustic emission collection system. The maximum axial test force of the loading system is $1000 \mathrm{kN}$, as shown in Figure 4. The multiple control modes, such as isokinetic strain, isokinetic displacement, displacement maintaining, and force maintaining, could be realized in the loading process. The acoustic emission monitoring was applied by using DS2-8B acoustic emission collection acquisition system made by Beijing Ruandao. This system not only can collect and record acoustic emission information automatically but also makes direct statistics on acoustic emission indicators of acoustic emission ringing counts and energy counts in unit time. To construct the three-dimensional AE spatial distribution, four acoustic emission probes were fixed before and after the gas coal sample. The amplification factor of the preamplifier was set to $40 \mathrm{~dB}$. During the test, the threshold value was $40 \mathrm{~dB}$, and the sampling frequency was $3 \mathrm{MHz}$.

3.2. Test Program. The cylinder samples $(\varphi 50 \mathrm{~mm} \times 100 \mathrm{~mm})$ were chosen in the static loading test. After preparation of samples, the acoustic emission acquisition system was connected, and the instruments were debugged. Samples were placed between the upper and lower pressure heads. The upper and lower ends of samples were uniformly coated with Vaseline to reduce influences of friction at ends on test results. The stress-strain relationship of samples in the postpeak stage could be gained by the axial displacement control method. Therefore, the test loading was applied by displacement control, and the loading speed was set to 


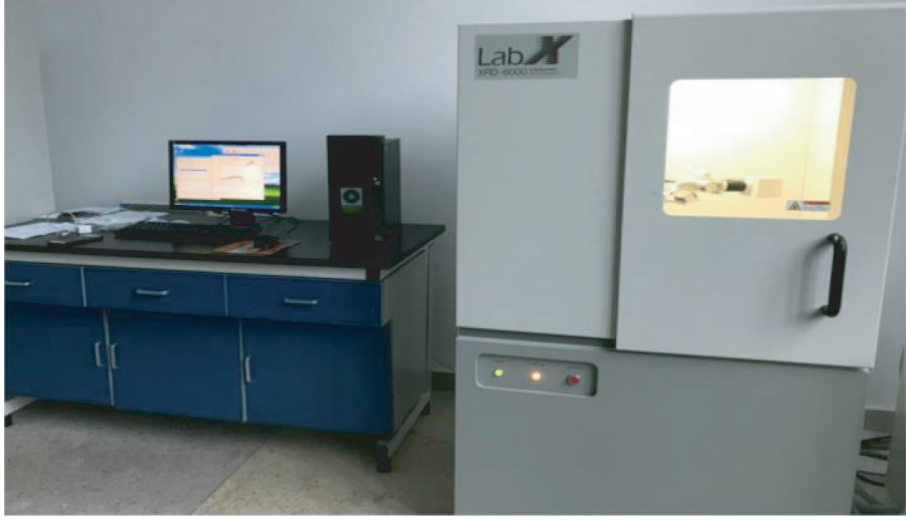

(a)

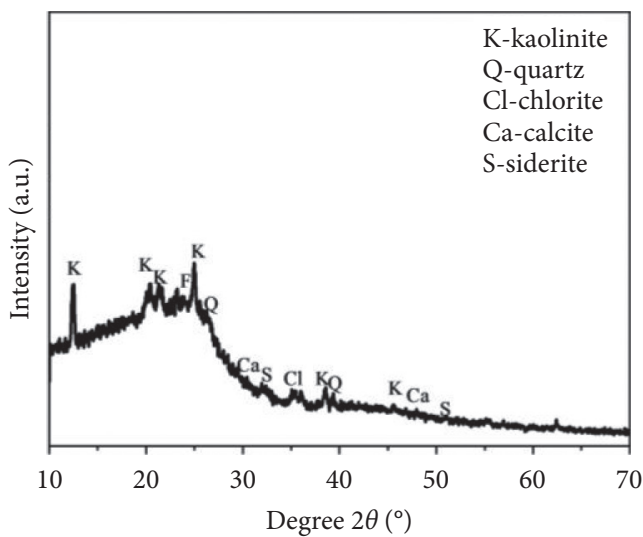

(b)

FIGURE 1: XRD test of gas coal: (a) X-ray diffractometer; (b) XRD pattern.
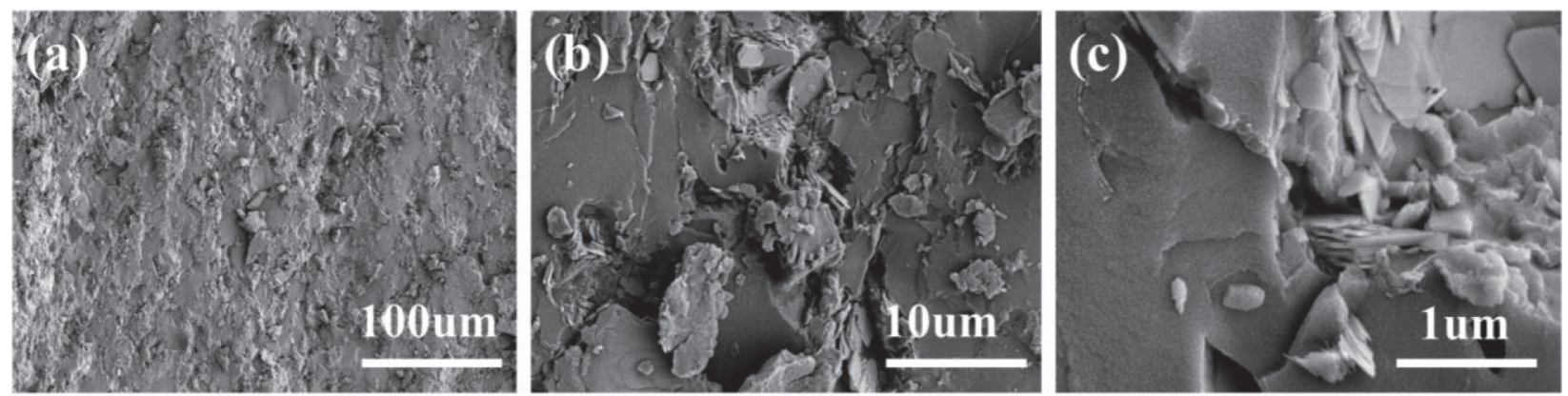

Figure 2: SEM images of gas coal.

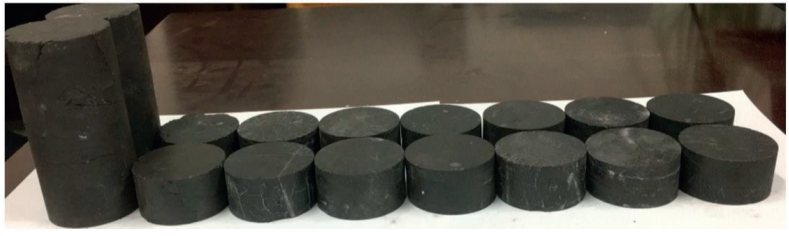

Figure 3: The picture of gas coal samples.

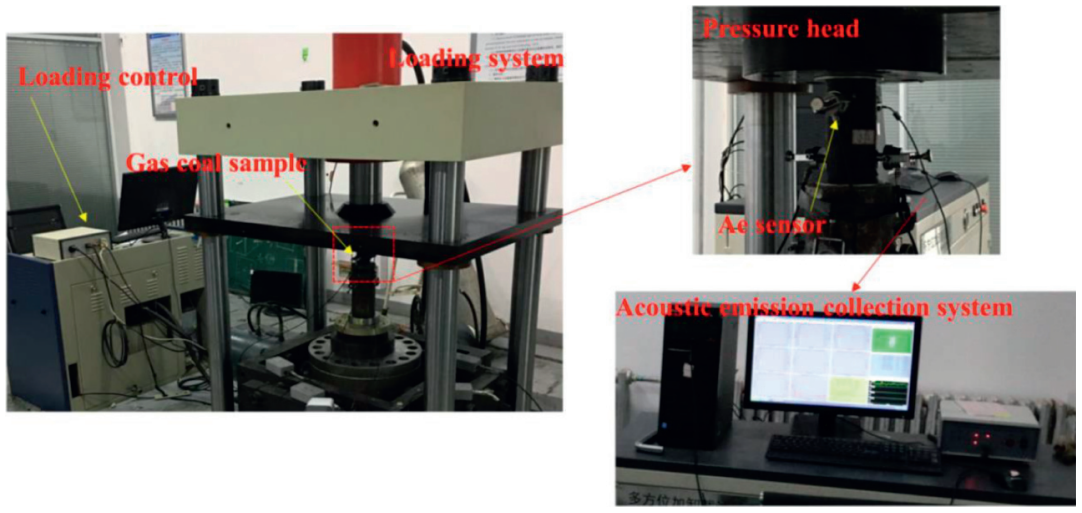

Figure 4: Static loading test system.

$0.002 \mathrm{~mm} / \mathrm{s}$ until the sample fracture. In the test process, the failure characteristics of gas coal could be recorded, and the stress-strain curves in the loading process were drawn.
Meanwhile, the acoustic emission signals were monitored and collected in the failure process of samples to analyze the internal damage features in the whole process of 
compression test for gas coal. In addition, Vaseline was used as the coupling agent of AE sensor to enhance the coupling effect.

\section{SHPB Dynamic Impact Test of Gas Coal}

4.1. Test Equipment. The dynamic impact test was applied by SHPB system of Key Laboratory of Safety and High-Efficiency Coal Mining, Ministry of Education, which was constructed by Anhui University of Science and Technology. The test equipment system and bullet size are shown in Figure 5.

Impact test was performed by isometric loading method of sample and bar. The diameter of incident bar, transmission bar, and absorption bar was $50 \mathrm{~mm}$, and the lengths were $2.0,1.5$, and $0.5 \mathrm{~m}$, respectively. These bars were made of high-strength alloy steel. The elasticity modulus was $200 \mathrm{GPa}$, and the yield strength was higher than $800 \mathrm{MPa}$. Spindle bullet made specifically in the experiment was used to produce half-sine stress wave to realize the loading of constant strain rate $[25,26]$.

In the test, the cylinder samples $(\varphi 50 \mathrm{~mm} \times 30 \mathrm{~mm})$ were placed between the incident bar and transmission bar. The spindle bullet driven by high-pressure nitrogen gas impacted onto the incident bar, and it formed an incidence pulse in the incident bar. When the incident pulse arrived at two ends of sample in the incident bar, the samples developed plastic deformation as a result of stress pulse. In the same time, some pulses were reflected, and the rest ran through samples and transmitted into the transmission bar, forming the reflection pulse signal and transmission pulse signal, respectively. Dynamic loads with different strengths were realized by adjusting the driven gas pressure. Three kinds of pulse signals were recorded by the resistance strain gauge ( $1 \mathrm{~m}$ away from the ends of sample) on the incident bar and semiconductor strain gauge on the transmission bar $(0.6 \mathrm{~m}$ away from the ends of sample). The applied strain gauge models and basic parameters are shown in Table 1. Signals were collected and acquired after amplification by the dynamic strain meter. Speed of the bullet was tested by speed measurement system composed of the timer and parallel beam.

According to two basic hypotheses of the SHPB experimental technology and Newton's Third Law [27], the data processing was implemented by the second wave method (equation (1)) $[14,26,28]$, through which the dynamic stress $(\sigma)$, strain $(\varepsilon)$, and strain rate $(\dot{\varepsilon})$ of gas coal sample were determined:

$$
\left\{\begin{array}{l}
\sigma=\frac{E A}{A_{0}} \varepsilon_{t}, \\
\varepsilon=-\frac{2 c_{0}}{l_{0}} \int_{0}^{t} \varepsilon_{r} \mathrm{~d} t \\
\dot{\varepsilon}=-\frac{2 c_{0}}{l_{0}} \varepsilon_{r} .
\end{array}\right.
$$

In equation (1), $\sigma$ is the dynamic stress of coal-rock mass, $\mathrm{MPa} ; \varepsilon$ is the dynamic strain of coal-rock mass; $\dot{\varepsilon}$ is the dynamic strain rate of coal-rock mass, $\mathrm{s}^{-1} ; \varepsilon_{r}$ and $\varepsilon_{t}$ are the strains of reflected wave and transmission wave, respectively; $c_{0}$ is the elastic wave velocity of pressure bar, $\mathrm{m} / \mathrm{s} ; E$ is the elasticity modulus of pressure bar material, $\mathrm{GPa} ; A$ is the cross-sectional area of pressure bar, $\mathrm{mm}^{2} ; A_{0}$ is the original cross-sectional area of coal-rock sample, $\mathrm{mm}^{2} ; l_{0}$ is the original length of coal-rock sample, $\mathrm{m}$.

4.2. Test Program. The impact tests of gas coal sample were performed under different impact gas pressures through the following steps:

(1) Tests were divided into four groups. The impact gas pressure was set at four levels according to the test design: $0.2,0.5,0.8$, and $1.1 \mathrm{MPa}$, respectively.

(2) Before the impact test, the strain gauges were pasted, and the operation condition of equipment was examined. Samples were installed between two pressure bars and coated with Vaseline to ensure that the samples closely contact with the incident bar and transmission bar. According to experimental design requirements, the working gas pressure was adjusted to realize different strain rate.

(3) The strain gauge was calculated, and data collection parameters were set, which can ensure that the data acquisition system is prepared. The bullet emission organization was started, and the impact gas pressure reached the set value. The bullet impacted onto the incident bar, and data were acquired and stored by the data storage processing system, accomplishing the same impact gas pressure test. Next, the impact gas pressure was adjusted, and the above steps were repeated. The different groups of impact tests were accomplished.

\section{Result Analysis of Static Loading Test for Gas Coal}

5.1. Deformation Characteristics of Gas Coal under Static Loading. Since stress-strain curves of the gas coals were similar under static loading, the stress-strain curve of coal sample (J1-2) in the full loading process is shown in Figure 6. Crack development of the gas coal sample under static loading experiences four stages: (1) The compaction stage of original micropores (OA section): micropores are compacted, and the stress-strain curve presents an upper concave shape. (2) Elastic deformation stage ( $A B$ section): micropores are further compressed and become compacted. The stress-strain curve is a straight line. (3) Dilation deformation stage (BC section): the stress-strain curve fluctuates and drops. The volume of coal sample changes from compression to dilation. In this stage, the original cracks expand, and they form the new induced cracks. (4) Postpeak failure stage (CD section): the stress-strain curve quickly drops, and coal samples develop slippage failure, manifested by brittle feature of coal samples. However, it is found that 


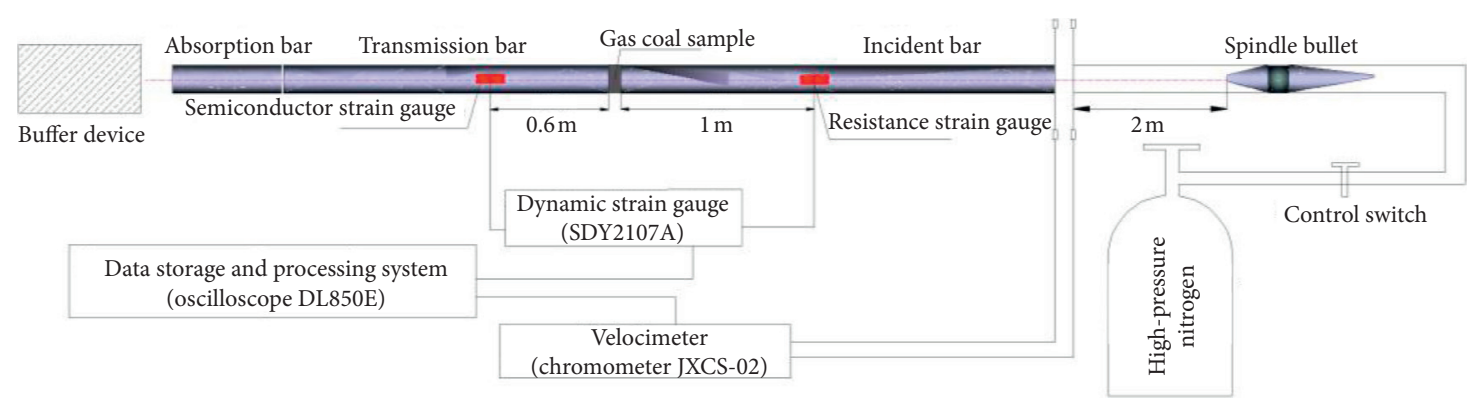

(a)

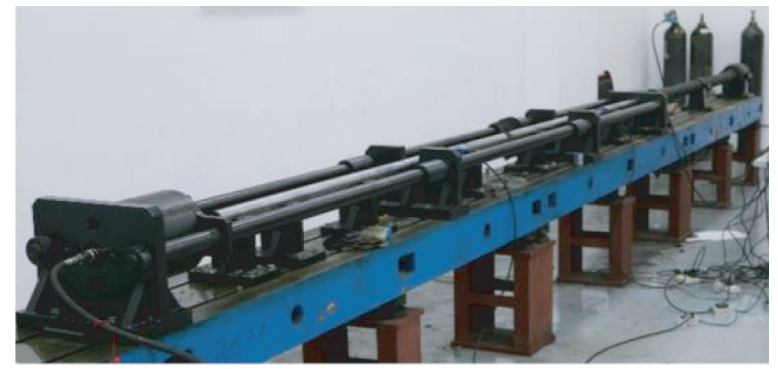

(b)

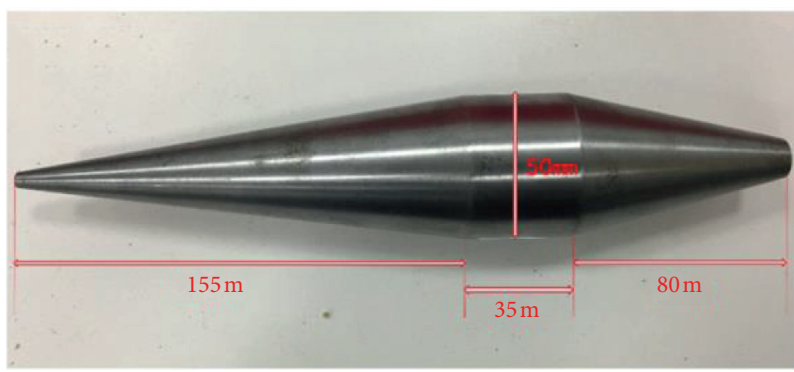

(c)

FIgURE 5: Schematic diagram of SHPB test device: (a) equipment system, (b) test equipment, and (c) spindle bullet.

TABLE 1: Basic parameters of the strain gauge.

\begin{tabular}{|c|c|c|c|c|c|}
\hline \multirow{2}{*}{ Resistance strain gauge } & Model & $\begin{array}{c}\text { Resistance } \\
(\Omega)\end{array}$ & $\begin{array}{l}\text { Sensitivity } \\
\text { coefficient }\end{array}$ & $\begin{array}{l}\text { Grid length } \times \text { grid width } \\
(\mathrm{mm})\end{array}$ & $\begin{array}{c}\text { Base size (length } \times \text { width }) \\
(\mathrm{mm})\end{array}$ \\
\hline & $\begin{array}{l}\text { BX120- } \\
2 \mathrm{AA}\end{array}$ & $119.8 \pm 0.1$ & $2.08 \pm 1 \%$ & $2 \times 1$ & $6 \times 3$ \\
\hline \multirow{2}{*}{$\begin{array}{l}\text { Semiconductor strain } \\
\text { gauge }\end{array}$} & Model & $\begin{array}{l}\text { Resistance } \\
(\Omega)\end{array}$ & $\begin{array}{l}\text { Sensitivity } \\
\text { coefficient }\end{array}$ & Silicon bar size (mm) & $\begin{array}{l}\text { Base size }(\text { length } \times \text { width }) \\
(\mathrm{mm})\end{array}$ \\
\hline & TP-5-120 & 120 & $110 \pm 5 \%$ & $5 \times 0.30 \times 0.05$ & $6 \times 4$ \\
\hline
\end{tabular}

the coal samples still keep good completion, instead of grinded state (Figure 6(b)). After the processing of test data, the uniaxial compressive strength of gas coal is $18.1 \mathrm{MPa}$, and the elasticity modulus is $0.931 \mathrm{GPa}$. Uniaxial compressive strengths of coal samples (J1-1 and J1-3) are 13.4 and $15.6 \mathrm{MPa}$, respectively, while the elasticity moduli are 0.568 and $0.871 \mathrm{GPa}$, respectively.

5.2. Acoustic Emission Features of Gas Coal under Static Loading. The features of acoustic emission are generally characterized by some parameters, such as energy, ringing count, and peak count [29]. Figure 7 shows the relation curves of stress, acoustic emission ringing count, and energy with time in the loading process. It is well known that acoustic emission signals reflect the internal damage of coal sample. They are closely related to the compaction of internal original cracks as well as development, expansion, and connection of new cracks. It can be seen that the variation trend of the stress-time curve of coal sample is consistent with those of acoustic emission ringing counts/energy-time curves. Therefore, the deformation failure of coal sample can be represented by the acoustic emission changes. Furthermore, acoustic emission features are different in different stages. The acoustic emission ringing counts and energy continuously increase with the continuous increase of loads, showing evident stage characteristic. In the OA section, there are few acoustic emission signals, which are mainly 


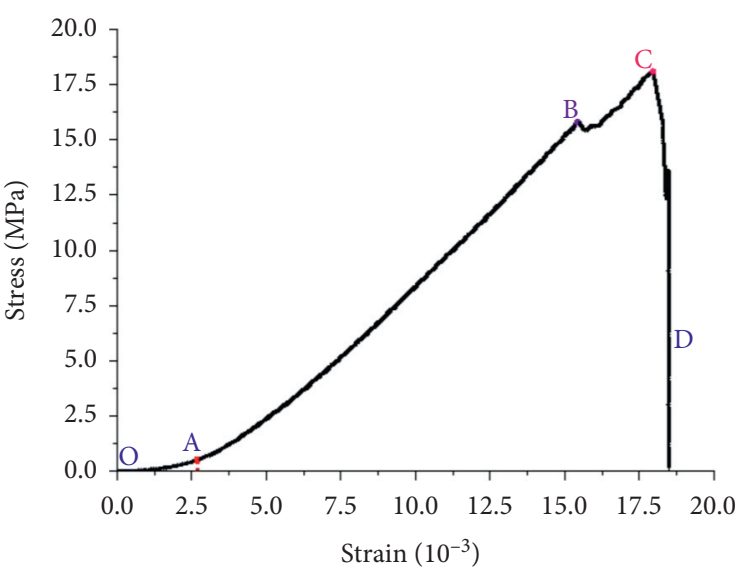

(a)

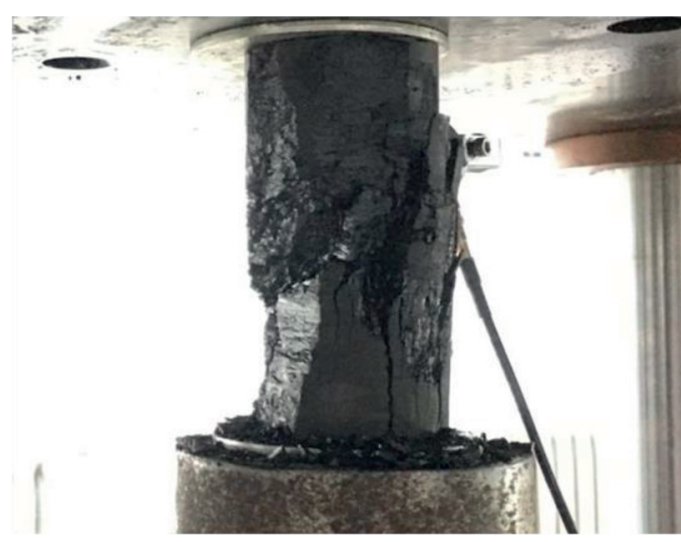

(b)

FiguRE 6: Static loading test results of gas coal: (a) stress-strain curve; (b) typical failure mode.

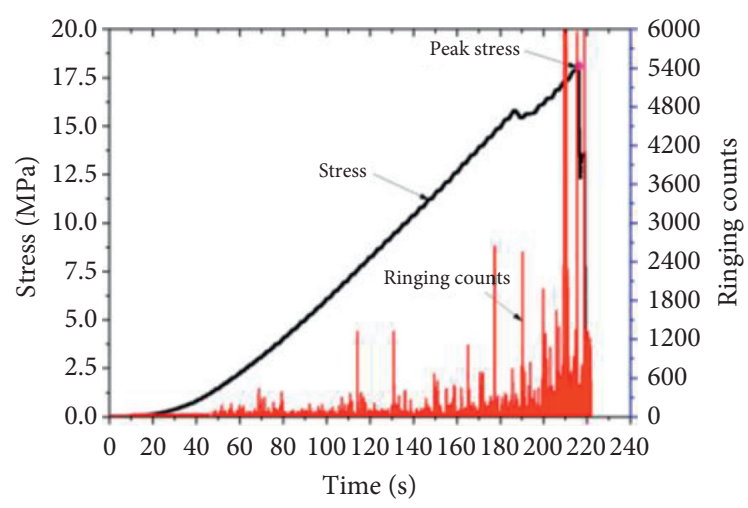

(a)

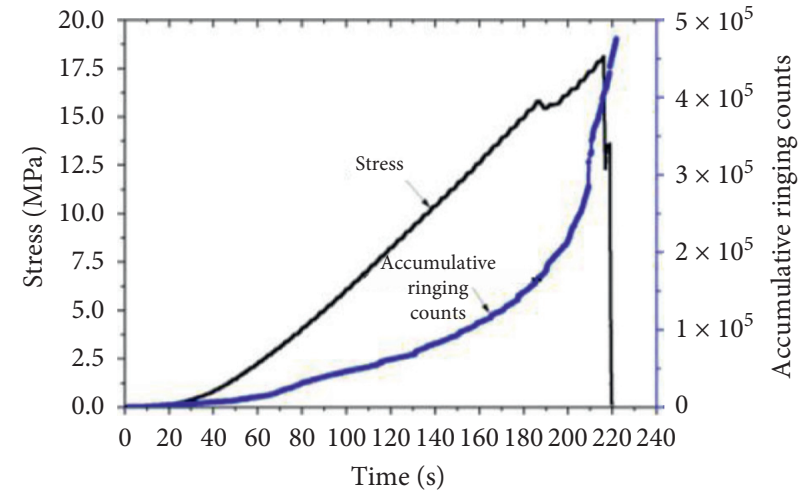

(b)

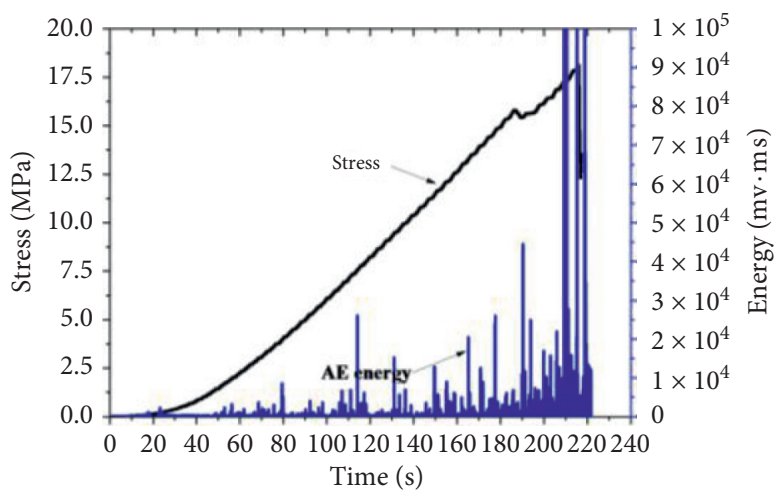

(c)

Figure 7: Acoustic emission test results: (a) acoustic emission ringing counts, (b) accumulative acoustic emission ringing counts, and (c) acoustic emission energy.

produced by closure of the original cracks. In early period of AB stage, there were still few acoustic emission signals. When the loads increase to the yield point of coal sample, the acoustic emission signals are enhanced, and stress fluctuates in a small range. In the $\mathrm{BC}$ stage, the internal cracks of coal sample continuously propagate and connect. When stress reaches the ultimate strength of coal sample, acoustic emission signals increase to the maximum and then samples fail, resulting in the sharp reduction of acoustic emission signals. Figure 7 (a) shows the relation curve of stress, acoustic emission ringing count, and time in the loading process. It is found that when the coal sample is loaded into the late elastic deformation stage, the acoustic emission ringing count gradually increases and fluctuates. The acoustic emission ringing count quickly increases with the increase of stress during the expansion and deformation 
stage, while it decreases rapidly after the coal sample is destroyed. The accumulative acoustic emission ringing counts are shown in Figure 7(b). The result suggests that, in the compaction stage and elastic deformation stage, the accumulative ringing count increases slowly. However, it increases suddenly until the coal sample becomes unstable and fails after entering the expansion deformation stage. Figure 7 (c) shows the acoustic emission energy change in the test. The acoustic emission energy value is at a low level in the compaction stage and elastic deformation stage, but it keeps increasing after entering the expansion deformation stage. It indicates that the coal fracture is due to the fact that the rock releases energy outward to aggravate the failure of the sample. A large amount of AE energy is released before the macroscopic failure of the coal samples.

\section{Results Analysis of Dynamic Impact Test of Gas Coal}

In this experiment, a total of 20 impact tests of gas coal sample were accomplished, and 17 valid pieces of data were collected. The impact gas pressure in tests was $0.2-1.1 \mathrm{MPa}$, and the speed of impact bar was $5.277-19.821 \mathrm{~m} / \mathrm{s}$. The average strain rate of coal sample was $53.464-208.076 \mathrm{~s}^{-1}$. Test data are processed by equation (1), and the test results are listed in Table 2.

The time-history curves of loading strain rate of gas coal sample are shown in Figure 8. Under different impact velocities, all of gas coal samples can correspond to one section of strain rate platform. In other words, the approximate mean constant-strain rate of gas coal samples can be found, indicating the loading reasonability of spindle bullet in the test. It meets the analysis principle of SHPB, and the dynamic mechanical analysis of gas coal is reliable to a certain extent. Figure 9 shows the dynamic stress equilibrium curves of gas coal (sample no. 2-1). It is observed that the sum of incident stress and reflected stress waves "Inc $+\mathrm{Re}$ " is basically consistent with the transmitted stress wave "Tra." It suggests that the test results are valid and reliable. Moreover, the stress equilibrium of all samples was checked to ensure the validity and accuracy of the results.

6.1. Stress-Strain Curves. Figure 10 shows the uniaxial impact dynamic stress-strain curves of the typical samples under different strain rates. It can be observed that the curves under different strain rates basically have same variation trend. However, their curve characteristics are different to some extent due to the influences of strain rate. Based on analysis of Figure 10, the deformation failure of gas coal sample under impact loads can be generally summarized into four stages:

(1) Elastic deformation stage: stress straightly increases with the increase of strain. Due to the high impact velocity in the test process, the closure and compaction stage of macroscopic and microscopic defects are very short, and there is hardly concave downward for the curves. Instead, the curves directly enter into the linear elastic deformation stage. In early period of linear elastic stage, the curves overlap well under high or low impact velocity, indicating the good consistency of elasticity modulus of samples in the elastic deformation stage. In the late period of linear elastic stage, the slope of the linear elastic stage increases with the increase of impact velocity, accompanied with gradual increase of dynamic elasticity modulus.

(2) Evolutionary stage of microcracks: stress slowly increases with the increase of strain. Slope of the stress-strain curve is relieved compared with that of the linear elastic stage. Due to the slow increase of stress on the gas coal sample, microcracks are expanded and new cracks are produced. However, the accumulative energy of coal sample in this stage is inadequate to connect cracks. Under this circumstance, the plastic deformation takes the dominant role in deformation of samples.

(3) Crack propagation stage: stress-strain curve develops an upward convexity in this stage. Due to the continuous increase of stress, cracks quickly propagate and connect with the main cracks, finally resulting in run-through failures of samples. Samples present overall failure. In the end of this stage, the stress of coal sample reaches the maximum, and the corresponding strain is the peak strain.

(4) Unloading stage: stress decreases with the increase of strain, manifested by strain softening. However, the decrease amplitude and strain rate are closely related to failure degree of samples. It is found that internal microcracks of gas coal sample present different development degrees under different strain rates, which is the main cause of fluctuation and different characteristics of the postpeak curve.

In comparison with stress-strain curves under different strain rates, there are obvious differences between peak strength and peak strain. With the increase of strain rate, both peak strength and peak strain increase, showing the positive correlation. It presents an evident strain rate effect. Compared with stress-strain curves under static loading condition, the postpeak effect of stress-strain curves is relatively evident under dynamic impact. It can be interpreted as follows: under the action of dynamic load, the postpeak effect of stress-strain curve does not show the characteristic that the stress decreases sharply with the strain, so it has the postpeak softening characteristic.

6.2. Change Characteristics of Peak Stress. As an important technological parameter in the coal cutting process, dynamic compressive strength (peak stress) represents the ultimate bearing capacity of coal under high strain rate. Figure 11 shows the variation curve of peak stress under different strain rates. It can be seen that the peak stress of gas coal gradually increases with the increase of strain rate. When the strain rate increases from 58.840 to $101.416 \mathrm{~s}^{-1}$, the peak stress sharply increases by $13.1 \mathrm{MPa}$, which is from 20.9 to 34.1 MPa. When the strain rate increases from 101.416 to 
TAble 2: Dynamic impact test results of gas coal (seam no. 13-1) in Pansan Coal Mine.

\begin{tabular}{|c|c|c|c|c|c|c|c|c|c|c|c|}
\hline \multirow{2}{*}{$\begin{array}{l}\text { Sample } \\
\text { number }\end{array}$} & \multirow{2}{*}{$\begin{array}{l}\text { Impact } \\
\text { gas } \\
\text { pressure } \\
(\mathrm{MPa})\end{array}$} & \multicolumn{2}{|c|}{$\begin{array}{l}\text { Velocity of impact } \\
\text { bar }\left(\mathrm{m} \cdot \mathrm{s}^{-1}\right)\end{array}$} & \multicolumn{2}{|c|}{$\begin{array}{l}\text { Average strain rate } \\
\qquad\left(\mathrm{s}^{-1}\right)\end{array}$} & \multirow{2}{*}{$\begin{array}{l}\text { Maximum } \\
\text { strain rate } \\
\qquad\left(\mathrm{s}^{-1}\right)\end{array}$} & \multicolumn{2}{|c|}{ Peak stress $(\mathrm{MPa})$} & \multirow{2}{*}{$\begin{array}{c}\text { Peak } \\
\text { strain } \\
(\%)\end{array}$} & \multirow{2}{*}{$\begin{array}{c}\text { Mixed } \\
\text { dynamic } \\
\text { elasticity } \\
\text { modulus } \\
(\mathrm{GPa})\end{array}$} & \multirow{2}{*}{$\begin{array}{l}\text { Failure } \\
\text { mode }\end{array}$} \\
\hline & & $\begin{array}{l}\text { Single } \\
\text { sample }\end{array}$ & $\begin{array}{l}\text { Arithmetic } \\
\text { mean value }\end{array}$ & $\begin{array}{l}\text { Single } \\
\text { sample }\end{array}$ & $\begin{array}{l}\text { Arithmetic } \\
\text { mean value }\end{array}$ & & $\begin{array}{l}\text { Single } \\
\text { sample }\end{array}$ & $\begin{array}{l}\text { Arithmetic } \\
\text { mean value }\end{array}$ & & & \\
\hline $1-1$ & \multirow{5}{*}{0.2} & 5.879 & \multirow{5}{*}{5.534} & 64.013 & \multirow{5}{*}{58.840} & 78.754 & 19.274 & \multirow{5}{*}{20.946} & 5.753 & 3.350 & Splitting \\
\hline $1-2$ & & 5.985 & & 53.464 & & 60.545 & 22.413 & & 4.576 & 4.898 & Splitting \\
\hline $1-3$ & & 5.429 & & 58.377 & & 76.872 & 19.026 & & 5.648 & 3.369 & Crushing \\
\hline $1-4$ & & 5.277 & & 58.233 & & 68.781 & 21.894 & & 4.446 & 4.925 & Splitting \\
\hline $1-5$ & & 5.098 & & 60.111 & & 70.803 & 22.121 & & 3.766 & 5.874 & Crushing \\
\hline $2-1$ & \multirow{4}{*}{0.5} & 12.120 & \multirow{4}{*}{12.157} & 100.650 & \multirow{4}{*}{101.416} & 108.423 & 33.942 & \multirow{4}{*}{34.061} & 4.880 & 6.955 & Crushing \\
\hline $2-2$ & & 12.147 & & 101.647 & & 106.031 & 31.742 & & 4.800 & 6.613 & Crushing \\
\hline $2-4$ & & 12.155 & & 97.402 & & 101.256 & 35.912 & & 5.726 & 6.272 & Crushing \\
\hline $2-5$ & & 12.204 & & 105.965 & & 115.406 & 34.648 & & 5.793 & 5.981 & Crushing \\
\hline $3-2$ & \multirow{4}{*}{0.8} & 16.130 & \multirow{4}{*}{16.327} & 148.499 & \multirow{4}{*}{144.290} & 172.063 & 45.770 & \multirow{4}{*}{45.770} & 6.023 & 7.599 & Crushing \\
\hline $3-3$ & & 16.548 & & 148.035 & & 149.481 & 43.515 & & 6.195 & 7.024 & Crushing \\
\hline $3-4$ & & 16.279 & & 140.113 & & 146.292 & 44.611 & & 5.016 & 8.894 & Crushing \\
\hline $3-5$ & & 16.351 & & 140.512 & & 148.883 & 40.246 & & 4.910 & 8.197 & Crushing \\
\hline $4-2$ & \multirow{4}{*}{1.1} & 19.821 & \multirow{4}{*}{19.603} & 200.447 & \multirow{4}{*}{201.212} & 217.325 & 48.102 & \multirow{4}{*}{49.763} & 4.982 & 9.655 & Grinding \\
\hline $4-3$ & & 19.807 & & 200.909 & & 218.712 & 50.147 & & 5.265 & 9.525 & Crushing \\
\hline $4-4$ & & 19.773 & & 208.076 & & 249.849 & 52.376 & & 5.836 & 8.975 & Grinding \\
\hline $4-5$ & & 19.011 & & 195.416 & & 226.518 & 48.425 & & 5.152 & 9.399 & Crushing \\
\hline
\end{tabular}

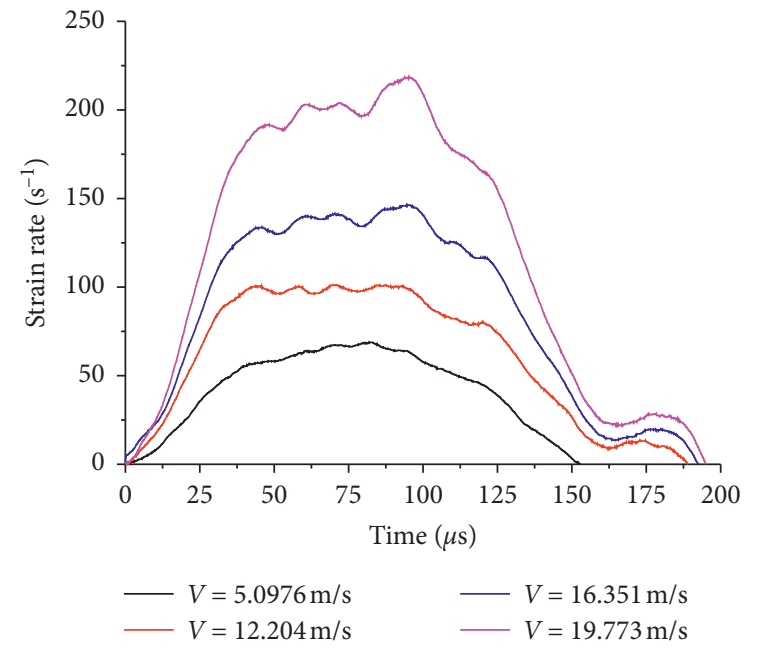

FIGURE 8: Time-history curves of loading strain rate of gas coal sample.

$144.290 \mathrm{~s}^{-1}$, peak stress is increased by $11.7 \mathrm{MPa}$. When the strain rate increases from 144.290 to $201.212 \mathrm{~s}^{-1}$, peak stress is increased by $4.0 \mathrm{MPa}$, which is from 45.8 to $49.8 \mathrm{MPa}$.

According to change characteristics of peak stress with strain rate, the functional relationship between them is fitted:

$$
\sigma_{d}=-75.097+23.652 \ln \dot{\varepsilon}, \quad R^{2}=0.967 .
$$

From equation (2), it can be observed that the dynamic compressive strength is highly correlated with strain rate. The increase of strain rate can enhance ultimate bearing capacity of gas coal. However, the dynamic compressive strength gently increases with the gradual increase of strain rate. These findings conform to the previous results reported by other scholars [30].

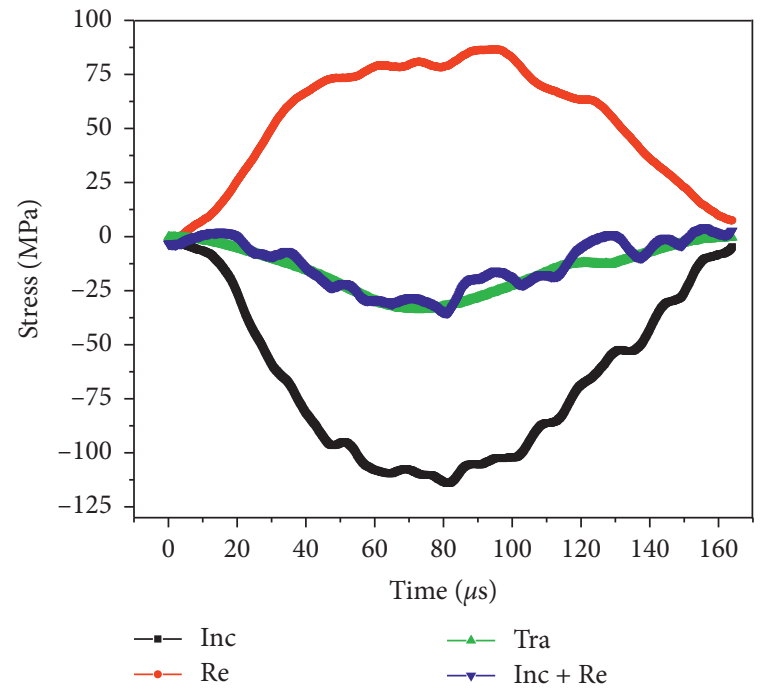

FIgURE 9: Dynamic stress equilibrium curves of gas coal ("Inc" is incident stress, "Re" is reflected stress, "Tra" is transmitted stress, and "Inc + Re" is superimposed stress at the end of incident bar).

6.3. Change Characteristics of Dynamic Increase Factor. Dynamic increase factor (DIF), the ratio between dynamic compressive strength and static compressive strength of gas coal sample, was used to measure the variation amplitude of compressive strength of gas coal with strain rate under different impact loads. It can be expressed as DIF $=f_{c, d} / f_{c, s}$, where $f_{c, d}$ and $f_{c, s}$ are dynamic and static compressive strengths of gas coal, MPa. The variation curve of DIF with strain rate is shown in Figure 12. It is found that DIF of the sample increases with the increase of strain rate, which shows two stages: (1) DIF quickly increases when the strain rate increases from 58.840 to $144.290 \mathrm{~s}^{-1}$. (2) When the 


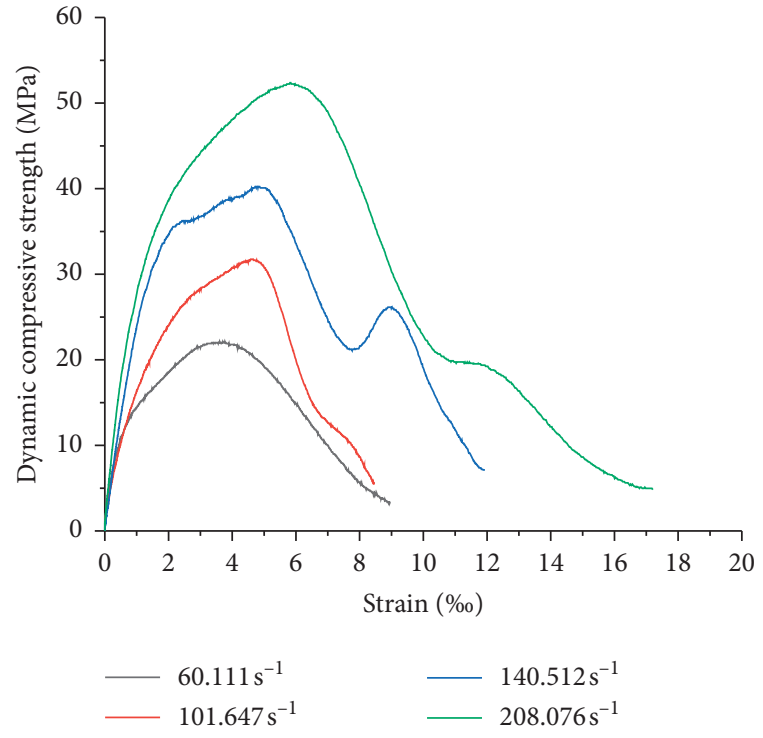

FIgURE 10: Stress-strain curve of gas coal samples under different strain rates.

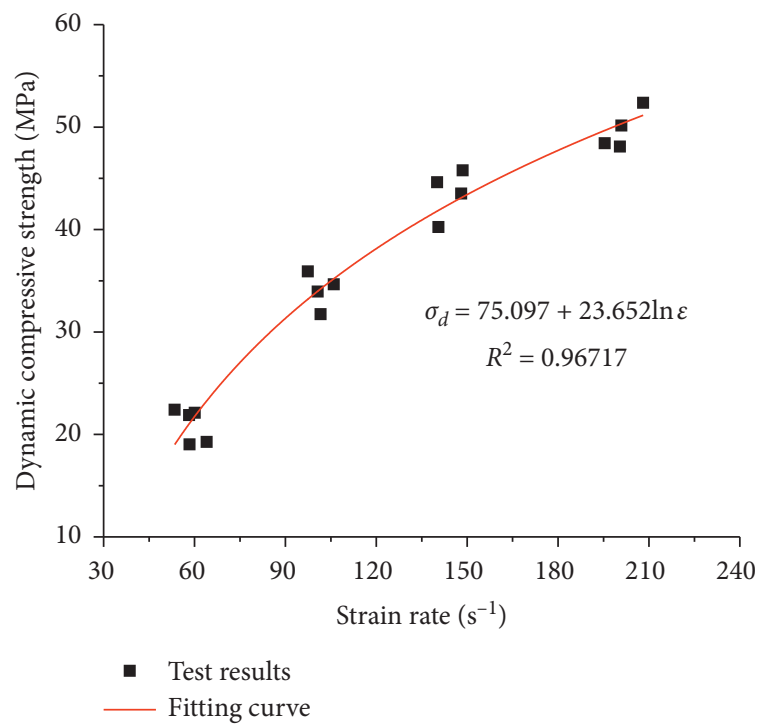

FIgURE 11: Variation curve of dynamic compressive strength with strain rate.

strain rate increases from 144.290 to $201.212 \mathrm{~s}^{-1}$, the growth range of DIF decreases obviously compared with the previous stage. It indicates that, under the different strain rates, sensitive degrees of DIF to strain rate are different for gas coal sample, and there exists one critical strain rate.

6.4. Change Characteristics of Mixed Dynamic Elasticity Modulus. The change of dynamic elasticity modulus reflects mechanical property of material under dynamic loading failure, representing material resistance to deformation. Before the dynamic loading failure, the stress-strain curve of coal-rock mass is nonlinear. Therefore, the numerical value of elasticity modulus is related to the chosen reference point. Under the effect of one-dimensional uniaxial stress $\sigma(t)$, the

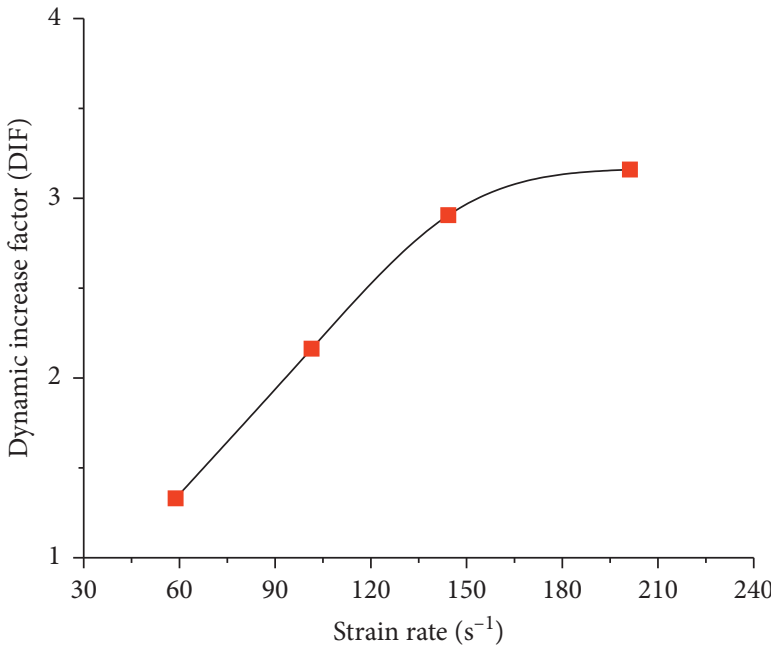

FIGURE 12: Variation curve of DIF with strain rate.

corresponding strain response is $\varepsilon(t)$. Thus, the dynamic elasticity modulus is $E_{d}=\sigma(t) / \varepsilon(t)$. That is the secant modulus at any moment $t$. The dynamic elasticity modulus could be obtained by processing the stress-strain curve before the stress limit. For the convenience of analysis, the peak stress and corresponding strain were calculated for analysis of mixed dynamic elasticity modulus [26]. The change curve of mixed dynamic elasticity modulus with strain rate is shown in Figure 13.

Due to differences of test samples, there is certain discretion of mixed dynamic elasticity modulus under the same strain rate. However, the mixed dynamic elasticity modulus increases gradually with the increase of strain rate, showing evident correlation with strain rate. When the strain rate increases from 58.840 to $201.212 \mathrm{~s}^{-1}$, the arithmetic mean values of mixed dynamic elasticity modulus are 4.481, 6.455, 7.928 , and $9.388 \mathrm{GPa}$, respectively. The increments of mixed dynamic elasticity modulus are $1.974,1.473$, and $1.460 \mathrm{GPa}$, respectively.

According to change characteristics of mixed dynamic elasticity modulus with strain rate, the functional relationship between them is fitted:

$$
E_{d}=2.731+0.033 \dot{\varepsilon}, \quad R^{2}=0.987 .
$$

It can be seen that, with the increase of strain rate, the mixed dynamic elasticity modulus conforms to the linear growth law. These research results are in agreement with the conclusions reported by the previous literature [31].

6.5. Dynamic Failure Characteristics of Gas Coal Sample. Failure morphology of gas coal samples under different strain rates is shown in Figure 14. All of gas coal samples have been damaged under different strain rates. With the increase of strain rate, the size of gas coal samples after damage significantly decreases, and the number of fragments dramatically increases. For the strain rates of 53.464 and $105.965 \mathrm{~s}^{-1}$, the failure degrees of gas coal samples are generally low. There are great block-like gas coals, showing 


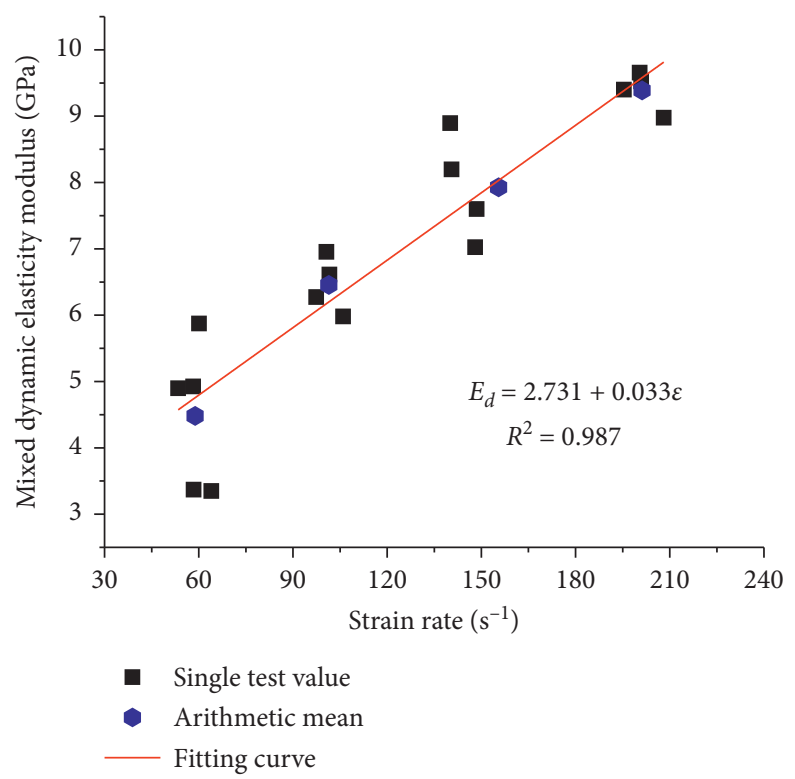

FIgURE 13: Change curve of the mixed dynamic elasticity modulus with the strain rate.

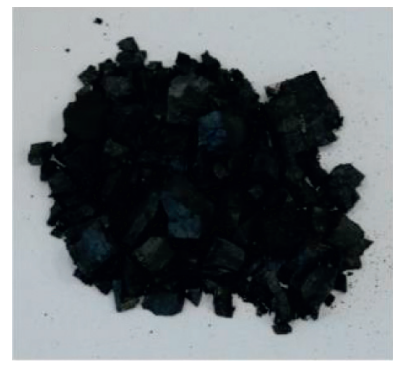

(a)

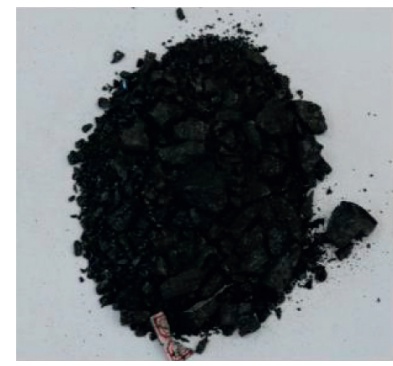

(b)

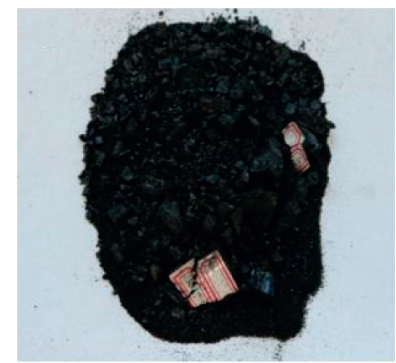

(c)

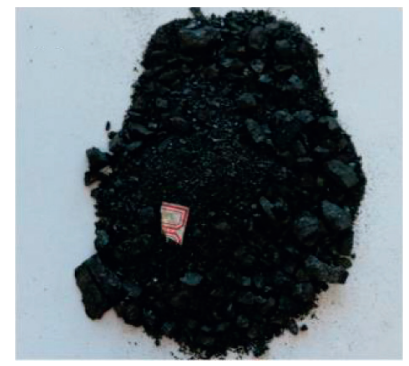

(d)

FIGURE 14: Failure morphology of gas coal samples under different strain rates: (a) $64.013 \mathrm{~s}^{-1}$; (b) $97.402 \mathrm{~s}^{-1}$; (c) $148.499 \mathrm{~s}^{-1}$; (d) $195.416 \mathrm{~s}^{-1}$.

good lump coal degree. Meanwhile, the coal samples present a splitting failure pattern. When the strain rate increases from 140.113 to $208.076 \mathrm{~s}^{-1}$, the coal samples present the compression failure pattern, and the number of small blocks increases after the failure of gas coal samples. This phenomenon can be explained by the fact that the input energy is positively related with strain rate, thus intensifying internal crack propagation of samples. Thus, the failure mode of samples changes from block-like pattern into powder-like pattern.

6.6. Energy Dissipation Law of Gas Coal Sample. Deformation failure of gas coal is the process from local dissipation fracture to the overall catastrophe. Actually, it is one state instable phenomenon under the energy driving, manifested by energy accumulation, transfer, and instant release [32]. Therefore, the dissipated energy is used to measure failure difficulty of gas coal sample. Hopkinson bar technique is based on the level-1 elastic wave theory and uniformity hypothesis. The expression of energy carried by the stress wave $\sigma(t)$ can be simplified as $W=\left(A_{e} c_{e} / E_{e}\right) \int_{0}^{t} \sigma^{2}(t) \mathrm{d} t=A_{e} E_{e} c_{e} \int_{0}^{t} \varepsilon^{2}(t) \mathrm{d} t$, where $A_{e}$ is the cross-sectional area of the input and output bars, $\mathrm{mm}^{2}$; $c_{e}$ is one-dimensional stress wave velocity, $\mathrm{m} / \mathrm{s}$; and $E_{e}$ is the elasticity modulus of input and output bars, MPa. It is assumed that all absorbed energies by gas coal sample are dissipated by cracking [33]. According to the energy conservation analysis, the dissipated energy by cracking of gas coal sample can be expressed as $W_{d}=W_{i}-\left(W_{r}+W_{t}\right)$, where $W_{d}$ is the total dissipated energy by coal-rock mass in dynamic impacts, $\mathrm{J} ; W_{i}, W_{r}$, and $W_{t}$ are incident energy, reflected energy, and transmission energy, J, respectively. To eliminate influence of sample dimension on dissipated energy, the dissipated energy density $w_{d}$ represents the energy dissipated by impact cracking of gas coal in unit volume: $w_{d}=W_{d} / V$, where $V$ is volume of samples, $\mathrm{mm}^{3}$. The energy dissipation strength of gas coal under different strain rates is measured by the energy dissipation rate $N$ : $N=W_{d} / W_{i}$. Table 3 shows the calculated results of energy dissipation for gas coal samples under different strain rates.

Figure 15 show change curves of incident energy, reflected energy, transmitted energy, and dissipated energy with strain rate. Obviously, incident energy, reflected energy, transmitted energy, and dissipated energy are positively 
TABLE 3: Calculated results of energy dissipation of gas coal samples under different strain rates.

\begin{tabular}{|c|c|c|c|c|c|c|c|}
\hline $\begin{array}{l}\text { Sample } \\
\text { number }\end{array}$ & $\begin{array}{l}\text { Strain rate } \\
\qquad\left(\mathrm{s}^{-1}\right)\end{array}$ & $\begin{array}{l}\text { Incident } \\
\text { energy }(J)\end{array}$ & $\begin{array}{c}\text { Reflected } \\
\text { energy }(J)\end{array}$ & $\begin{array}{c}\text { Transmitted } \\
\text { energy }(\mathrm{J})\end{array}$ & $\begin{array}{l}\text { Dissipated } \\
\text { energy }(\mathrm{J})\end{array}$ & $\begin{array}{c}\text { Dissipated energy } \\
\text { density }\left(\mathrm{J} / \mathrm{m}^{3}\right)\end{array}$ & $\begin{array}{c}\text { Energy } \\
\text { dissipation rate }\end{array}$ \\
\hline $1-1$ & 64.013 & 18.929 & 8.114 & 2.197 & 8.617 & 146302.502 & 0.455 \\
\hline $1-2$ & 53.464 & 14.553 & 4.647 & 2.733 & 7.174 & 121793.362 & 0.493 \\
\hline $1-3$ & 58.377 & 14.685 & 8.454 & 1.876 & 4.355 & 73935.298 & 0.297 \\
\hline $1-4$ & 58.233 & 13.086 & 6.485 & 2.228 & 4.373 & 74246.134 & 0.334 \\
\hline $1-5$ & 60.111 & 18.925 & 7.131 & 2.199 & 9.595 & 162895.482 & 0.507 \\
\hline $2-1$ & 100.650 & 35.377 & 17.908 & 4.487 & 12.983 & 220419.751 & 0.367 \\
\hline $2-2$ & 101.647 & 25.768 & 14.290 & 3.437 & 8.041 & 136515.447 & 0.312 \\
\hline $2-4$ & 97.402 & 40.395 & 17.237 & 5.758 & 17.400 & 295411.868 & 0.431 \\
\hline $2-5$ & 105.965 & 38.246 & 20.205 & 5.675 & 12.365 & 209932.700 & 0.323 \\
\hline $3-2$ & 148.499 & 73.622 & 39.174 & 6.291 & 28.157 & 478044.670 & 0.382 \\
\hline $3-3$ & 148.035 & 60.722 & 30.938 & 6.553 & 23.231 & 394416.678 & 0.383 \\
\hline $3-4$ & 140.113 & 60.610 & 29.690 & 8.202 & 22.718 & 385707.874 & 0.375 \\
\hline $3-5$ & 140.512 & 61.589 & 33.965 & 6.477 & 21.147 & 359034.649 & 0.343 \\
\hline $4-2$ & 200.447 & 116.486 & 60.682 & 8.044 & 47.760 & 810871.827 & 0.410 \\
\hline $4-3$ & 200.909 & 116.259 & 54.279 & 7.711 & 54.269 & 921367.920 & 0.467 \\
\hline $4-4$ & 208.076 & 146.504 & 80.635 & 7.765 & 58.104 & 986483.757 & 0.397 \\
\hline $4-5$ & 195.416 & 152.137 & 83.932 & 10.552 & 57.653 & 978522.920 & 0.392 \\
\hline
\end{tabular}

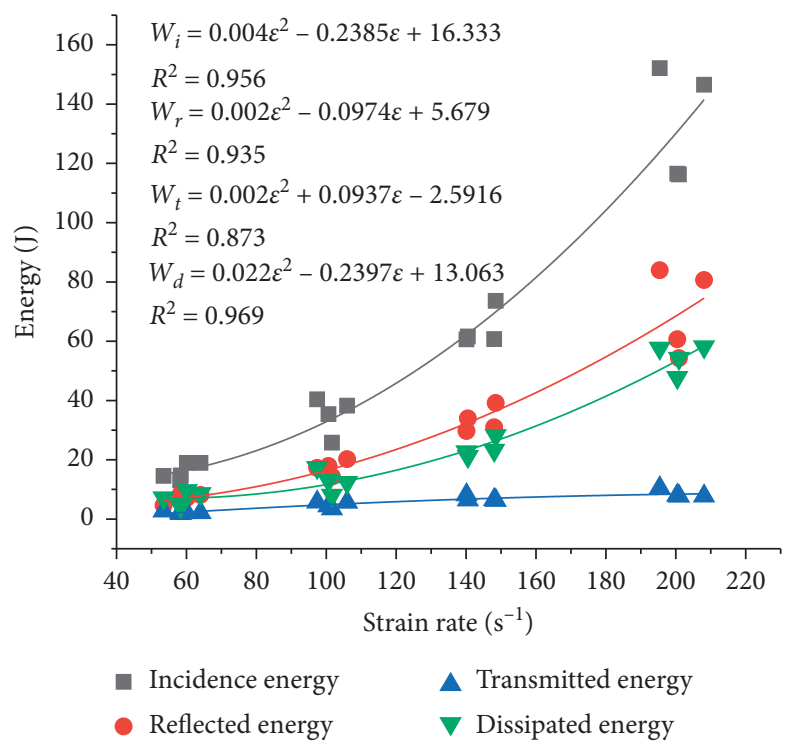

FIGURE 15: Relation curves of incident energy, reflected energy, transmitted energy, and dissipated energy with strain rate.

correlated with strain rate. Furthermore, the data analysis in Table 3 shows that the incident energy is high under different strain rates. But the transmitted energy is small, and it is significantly lower than the reflected energy. It can be contributed that when incident energy arrives at the end of incident bar and samples, most of the energy is reflected into the incident bar and forms the reflected energy. Most of the energies running through samples are absorbed by samples, and only few are transmitted into the transmitted bar, forming the transmission energy. Due to intensifying cracking of coal-rock mass, the generation of small fragments requires more cracks, while more energy is needed to generate and expand new cracks.

Generally speaking, the dissipated energy increases with the increase of incident energy. Figure 16 shows the change scatter diagram of energy dissipation rate with strain rate. Clearly, energy dissipation rate does not increase or decrease with the increase of strain rate. But it fluctuates in a certain range (0.3-0.5), and it is uncorrelated with strain rate. This is because the internal unevenness of gas coal sample results in large discretion of internal structure among different samples. Thus, there are great differences for energy propagation in samples.

Moreover, dynamic failure mechanism of gas coal is analyzed from the perspective of energy dissipation. Energy absorbed by samples is mainly dissipated in the evolution of microcracks. When the strain rate is low, the mesocracks that have small dissipated energy work on the deformation failure of gas coal. Before the absorbed energy increases to the value of other mesocracks opening and forming the main 


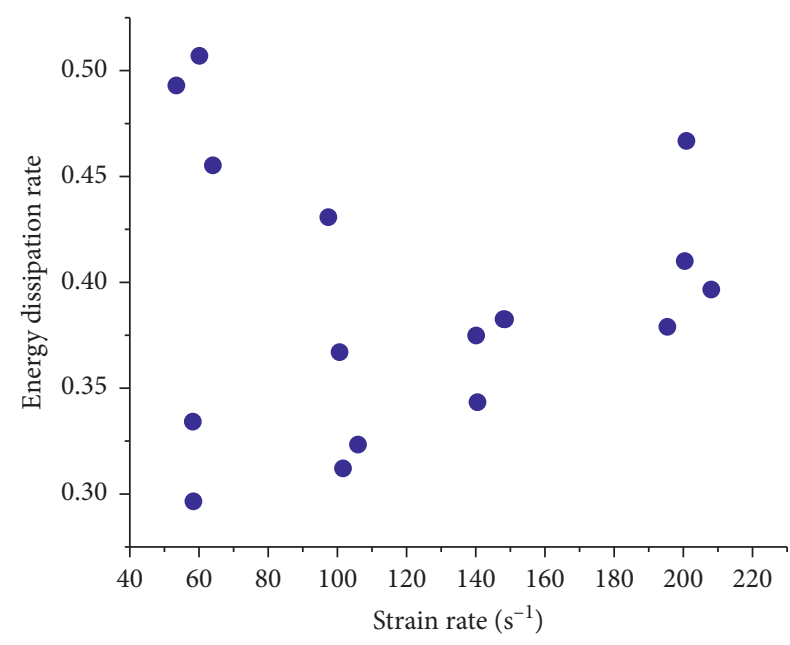

FIGURE 16: Relationship between energy dissipation rate and strain rate.

cracks, the expansion and connection of these mesocracks have caused splitting failure of materials. In the condition of low strain rate, the less mesocracks take the dominant role and the size of the fragments is larger. Therefore, the compressive strength is lower at the failure state, as shown in Figures 10 and 14(a). However, with the increase of strain rate, the absorbed energy of gas coal reaches the higher level, and the propagation of more mesocracks participates in the cracking process. Higher-level energy leads to smaller size of cracked materials. Under the cracking state, the compressive strength increases with the increase of strain rate, shown in Figures 10 and 14(b)-14(d).

\section{Contrastive Analysis of Energy under Different Loading Modes}

In the static uniaxial compressive test, the total absorbed energy density $u$ of sample is the area surrounded by stressstrain curve [34]: $u=\int \sigma \mathrm{d} \varepsilon$, where $\sigma$ is axial stress, $\mathrm{MPa}$, and $\varepsilon$ is axial strain. The total dissipated energy density $u_{d}$ is the difference between the total absorbed energy $u$ and the releasable strain energy density $u_{e}$. After static failure of sample, $u_{e} \approx 0$. That means that $u \approx u_{d}$. Therefore, the total failure absorbed energy density in static test can replace the total dissipated energy density at static failure. The total dissipated energy and energy density of gas coal are shown in Table 4 in static loading test.

Since there is some energy released by reflected wave and transmitted wave in the dynamic impact test, the energy comparison under different loading modes only considers energy dissipated by sample failure. Dissipated energy density reflects the energy dissipation during failure modes of samples with different sizes. By comparison with Tables 3 and 4 , for specimens no. 1-1 (64.013 $\mathrm{s}^{-1}$ strain rate) and 1-2 $\left(53.464 \mathrm{~s}^{-1}\right.$ strain rate), the dissipated energy density of gas coal sample is approximately equal to the dissipated energy density under static loading. However, by analyzing morphology after sample failure (Figures 6(b) and 14(a)), it is found that the crushing degree of sample under dynamic
TABLE 4: Total dissipated energy of gas coal failure in static loading test.

\begin{tabular}{lccc}
\hline $\begin{array}{l}\text { Sample } \\
\text { number }\end{array}$ & $\begin{array}{c}\text { Compressive } \\
\text { strength }(\mathrm{MPa})\end{array}$ & $\begin{array}{c}\text { Total } \\
\text { dissipated } \\
\text { energy }(\mathrm{J})\end{array}$ & $\begin{array}{c}\text { Total dissipated } \\
\text { energy density } \\
\left(\mathrm{J} \cdot \mathrm{m}^{-3}\right)\end{array}$ \\
\hline $\mathrm{J} 1-1$ & 13.4 & 23.12 & 117735.24 \\
$\mathrm{~J} 1-2$ & 18.1 & 28.37 & 144493.25 \\
$\mathrm{~J} 1-3$ & 15.6 & 29.19 & 148642.25 \\
\hline
\end{tabular}

impact is significantly higher than that under static loading. Therefore, the failure degree under dynamic impact is higher than that under static loading when the dissipated energy density is the same. In other words, gas coal sample under static loading needs to consume more energy to get the same crushing degree compared with that under dynamic impact.

\section{Conclusions}

(1) In static loading test, the stress-strain curve of gas coal sample is generally divided into four stages: original micropore compaction stage, elastic deformation stage, dilation deformation stage, and postpeak failure stage. With the increase of loads, acoustic emission characteristics present evident stage features. In the dilation deformation stage, the acoustic emission signal increases to the maximum value and then samples are damaged, resulting in the sharp reduction of acoustic emission signal.

(2) In dynamic impact test, the stress-strain curve of gas coal sample generally can be divided into four stages: elastic deformation stage, microcrack evolution stage, crack propagation stage, and unloading stage. Due to the high impact velocity, there is no micropore compaction stage compared with the static loading, and it enters into the elastic deformation stage. Dynamic compression strength, DIF, and mixed dynamic elasticity modulus are highly correlated with strain rate. Among them, DIF is sensitive to strain rate to different extents, and there is a critical strain rate. However, the mixed dynamic elasticity modulus follows the linear variation law.

(3) Under the dynamic impact, incident energy, reflected energy, transmitted energy, and dissipated energy are positively correlated with strain rate. However, energy dissipation rate fluctuates in a certain range with the increase of strain rate. It is a variable parameter unrelated to strain rate. The incident energy is high under different strain rates. But the transmitted energy is small, and it is significantly lower than the reflected energy. In addition, the dissipated energy of gas coal sample is small at low strain rate, and the sample develops a splitting failure mode. But the dissipated energy increases with the increase of strain rate. It needs more energy to generate and extend more new cracks. Therefore, the sample is further cracked, and it develops a cracking failure mode. 
(4) Dissipated energy densities of gas coal samples under static loading and dynamic impact are compared. Under the same dissipated energy density, the failure degree of sample under dynamic impact is higher than that under static loading. In other words, it needs to consume more energy to get equal crashing degree under static loads compared with that under dynamic impact.

\section{Data Availability}

The data used to support the findings of this study are available from the corresponding author upon request.

\section{Conflicts of Interest}

The authors declare that they have no conflicts of interest.

\section{Acknowledgments}

This work was financially supported by the National Natural Science Foundation of China (nos. 52004005, 51974009, 51874002, 51774012, and 52074006), Anhui Provincial Natural Science Foundation (nos. 2008085QE222 and 2008085QE260), Independent Research Fund of the State Key Laboratory of Mining Response and Disaster Prevention and Control in Deep Coal Mines (Anhui University of Science and Technology (no. SKLMRDPC19ZZ012), Anhui University of Science and Technology Introduction of Talents Research Fund Project, Scholastic Key Project (no. QN2019113), Patent Transformation and Cultivation Project (no. ZL201907), National Key Research and Development Plan (no. 2017YFC0603003), and Anhui Provincial Key Research and Development Plan (no. 201904a07020010).

\section{References}

[1] J. Feng, E. Wang, X. Chen, and H. Ding, "Energy dissipation rate: an indicator of coal deformation and failure under static and dynamic compressive loads," International Journal of Mining Science and Technology, vol. 28, no. 3, pp. 397-406, 2018.

[2] Z. Li, L. Dou, W. Cai et al., "Investigation and analysis of the rock burst mechanism induced within fault-pillars," International Journal of Rock Mechanics and Mining Sciences, vol. 70, pp. 192-200, 2014.

[3] Y. Hao and H. Hao, "Numerical investigation of the dynamic compressive behaviour of rock materials at high strain rate," Rock Mechanics and Rock Engineering, vol. 46, no. 2, pp. 373-388, 2013.

[4] G. Zhao, L. Xie, and X. Meng, "A damage-based constitutive model for rock under impacting load," International Journal of Mining Science and Technology, vol. 24, no. 4, pp. 505-511, 2014.

[5] J. R. Klepaczko, T. R. Hsu, and M. N. Bassim, "Elastic and pseudo viscous properties of coal under quasi-static and impact loading," Canadian Geotechnical Journal, vol. 24, pp. 203-212, 2011.

[6] X. Li, F. Gong, M. Tao et al., "Failure mechanism and coupled static-dynamic loading theory in deep hard rock mining: a review," Journal of Rock Mechanics and Geotechnical Engineering, vol. 9, no. 4, pp. 767-782, 2017.
[7] Z. Tao, H. Zhang, Y. Chen, and C. Jiang, "Support principles of NPR bolt/cable and control techniques of large-deformation disasters," International Journal of Mining Science and Technology, vol. 26, no. 6, pp. 967-973, 2016.

[8] Y. Zhao, G.-F. Zhao, Y. Jiang, D. Elsworth, and Y. Huang, "Effects of bedding on the dynamic indirect tensile strength of coal: laboratory experiments and numerical simulation," International Journal of Coal Geology, vol. 132, pp. 81-93, 2014.

[9] Y. Wang and R. Yang, "Study of the dynamic fracture characteristics of coal with a bedding structure based on the NSCB impact test," Engineering Fracture Mechanics, vol. 184, pp. 319-338, 2017.

[10] Q. B. Zhang and J. Zhao, "A review of dynamic experimental techniques and mechanical behaviour of rock materials," Rock Mechanics and Rock Engineering, vol. 47, no. 4, pp. 1411-1478, 2013.

[11] M. L. Doan and A. Billi, "High strain rate damage of Carrara marble," Geophysical Research Letters, vol. 38, pp. 1-6, 2011.

[12] X. Zhang, Y.-W. Chiu, H. Hao, A. Hsieh, N. Salter, and J. Cui, "Dynamic compressive material properties of clay bricks at different strain rates," Construction and Building Materials, vol. 192, pp. 754-767, 2018.

[13] C. Li, Y. Xu, P. Chen, H. Li, and P. Lou, "Dynamic mechanical properties and fragment fractal characteristics of fractured coal-rock-like combined bodies in split Hopkinson pressure bar tests," Natural Resources Research, vol. 29, no. 5, pp. 3179-3195, 2020.

[14] X. H. Liu, R. Zhang, and J. F. Liu, "Dynamic test study of coal rock under different strain rates," Journal of Coal Science \& Engineering, vol. 37, no. 9, pp. 1528-1534, 2012.

[15] J. G. Wang, S. Zhang, and B. J. Xie, "Electromagnetic appearing characteristics of damage properties of coal under impact loading," Chinese Journal of Geotechnical Engineering, vol. 39, no. 9, pp. 1662-1669, 2017.

[16] Y. K. Fu, B. J. Xie, and Q. F. Wang, "Dynamic mechanical constitutive model of the coal," Journal of Coal Science \& Engineering, vol. 38, no. 10, pp. 1769-1774, 2013.

[17] R. L. Shan, R. Q. Cheng, and W. J. Gao, "Study on dynamic constitutive model of anthracite of Yunjialing coal mine," Journal of Rock Mechanics and Geotechnical Engineering, vol. 25, pp. 2258-2263, 2006.

[18] W. J. Gao and R. L. Chan, "Failure pattern and strength properties of anthracite under impact loading," Journal of the China Coal Society, vol. 37, no. s1, pp. 13-18, 2012.

[19] W. Wang, H. M. Li, and H. L. Gu, "Experimental study of strength characteristics of water-saturated coal specimens under 3D coupled static-dynamic loadings," Journal of Rock Mechanics and Geotechnical Engineering, vol. 36, pp. 24062414, 2017.

[20] L. Y. Yu, G. L. Li, H. J. Su, H. W. Jing, and T. Zhang, "Experimental study on static and dynamic mechanical properties of anthracite after high temperature heating," Journal of Rock Mechanics and Geotechnical Engineering, vol. 36, no. 11, pp. 2712-2719, 2017.

[21] B. J. Xie, Y. G. Cui, and J. G. Wang, "Experimental study on mechanics properties of coal impact damage," Safety in Coal Mines, vol. 44, no. 11, pp. 18-21, 2013.

[22] C. Fan, S. Li, D. Elsworth, J. Han, and Z. Yang, "Experimental investigation on dynamic strength and energy dissipation characteristics of gas outburst-prone coal," Energy Science \& Engineering, vol. 8, no. 4, pp. 1015-1028, 2020.

[23] A. Lu, S. Hu, M. Li, T. Duan, B. Li, and X. Chang, "Impact of moisture content on the dynamic failure energy dissipation 
characteristics of sandstone," Shock and Vibration, vol. 2019, Article ID 6078342, 10 pages, 2019.

[24] Q. Ping, H. Sun, C. Zhang, and X. Zhou, "Physics and dynamics characteristics and energy analysis of freeze-thaw limestone," Advances in Civil Engineering, vol. 2020, Article ID 8820172, 12 pages, 2020.

[25] X. B. Li, T. S. Lok, J. Zhao, and P. J. Zhao, "Oscillation elimination in the Hopkinson bar apparatus and resultant complete dynamic stress-strain curves for rocks," International Journal of Rock Mechanics and Mining Sciences, vol. 37, no. 7, pp. 1055-1060, 2000.

[26] B. J. Xie, X. Y. Wang, and P. Y. Lv, "Dynamic properties of bedding coal and rock and the SHPB testing for its impact damage," Journal of Vibration Shock, vol. 36, pp. 117-124, 2017.

[27] L. L. Wang, Foundation of Stress Waves, National Defense Industry Press, Beijing, China, 2005.

[28] L. Song and S. S. Hu, "Two-wave and three-wave method in SHPB data processing," Explosion and Shock Waves, vol. 25, pp. 368-373, 2005.

[29] M. Cai, H. Morioka, P. K. Kaiser et al., "Back-analysis of rock mass strength parameters using ae monitoring data," International Journal of Rock Mechanics and Mining Sciences, vol. 44, no. 4, pp. 538-549, 2007.

[30] M. Li, X. B. Mao, L. L. Cao, R. R. Mao, and H. Pu, "Experimental study on mechanical properties of coal under high strain rate," Journal of Mining and Safety Engineering, vol. 32, no. 2, pp. 317-324, 2015.

[31] D. K. Wang, S. M. Liu, J. P. Wei, B. H. Yao, and M. Peng, "The failure characteristics of coal under impact load in laboratory," Journal of Mining and Safety Engineering, vol. 34, pp. 594-600, 2017.

[32] X. Liu, X. Wang, E. Wang et al., "Effects of gas pressure on bursting liability of coal under uniaxial conditions," Journal of Natural Gas Science and Engineering, vol. 39, pp. 90-100, 2017.

[33] Z. X. Zhang, S. Q. Kou, L. G. Jiang, and P.-A. Lindqvist, "Effects of loading rate on rock fracture: fracture characteristics and energy partitioning," International Journal of Rock Mechanics and Mining Sciences, vol. 37, no. 5, pp. 745-762, 2000.

[34] L. Y. Li, Z. Q. Xu, H. P. Xie, Y. Ju, X. Ma, and Z. C. Han, "Failure experimental study on energy laws of rock under differential dynamic impact velocities," Journal of Coal Science \& Engineering, vol. 36, no. 12, pp. 2007-2011, 2011. 